\title{
Tool Wear Analysis due to Machining In Super Austenitic Stainless Steel
}

\author{
Ashwin Polishetty, Mohanad Alabdullah and Guy Littlefair \\ School of Engineering, Deakin University, 3216 Waurn Ponds, VIC, Australia
}

\begin{abstract}
This paper presents tool wear study when a machinability test was applied using milling on Super Austenitic Stainless Steel AL6XN alloy. Eight milling trials were performed under two cutting speeds, $100 \mathrm{~m} / \mathrm{min}$ and $150 \mathrm{~m} / \mathrm{min}$, combined with two feed rates at $0.1 \mathrm{~mm} /$ tooth and $0.15 \mathrm{~mm} /$ tooth and two depth of cuts at $2 \mathrm{~mm}$ and $3 \mathrm{~mm}$. An Alicona 3D optical surface profilometer was used to scan cutting inserts flank and rake face areas for wear. Readings such as maximum and minimum deviations were extracted and used to analyse the outcomes. Results showed various types of wear were generated on the tool rake and flank faces. The common formed wear was the crater wear. The formation of the build-up edge was observed on the rake face of the cutting tool.
\end{abstract}

\section{Introduction}

Super austenitic stainless steel (SASS) alloy-AL6XN from now on referred as AL6XN is a type of austenite stainless steel distinguishable by its high alloying contents. The presence of alloying elements such as chromium, nickel, molybdenum and nitrogen enhance the resistance of the alloy to the stress corrosion cracking (SCC), crevice and pitting corrosion. AL6XN alloy is applied in various engineering applications such as in offshore structures, chemical waste processing, food containers, transformer cases and pump parts [1]-[3].

Contrary, the alloying elements render the alloy to be classified as a difficult to machine material. Machinability of a material is a criterion used to define the ease with which the material can be machined. In general, machinability is often judged by; the magnitude of cutting forces, tool wear/tool life, surface finish and surface integrity; and chips formation and morphology [4]. The machinability process is sensitive to the properties of the machined material, such as high level of strength, ductility, work hardening and decreased thermal conductivity [5]-[9]. Machinability studies have been conducted by researchers on different Austenitic Stainless Steel (ASS) grades.

The authors of this work conducted a recent study on machinability of AL6XN SASS alloy [10]. The cutting forces, surface microhardness and roughness were investigated when the alloy was machined under up end milling operation. A correlation between the machining aspects and the cutting parameters was explained.

Research study conducted by Nordin et.al says that flank, crater and chipping wear was observed during milling of 316 AISI austenite stainless steel [11]. Similarly, Abou-El-Hossein, K. and Z. Yahya [12] studied the machinability behaviour of AISI 304. Coated carbide inserts were used in an end milling operation. The main objective of the research was to evaluate the wear and life of the inserts. When high feed rate was used, the tool wear significantly decreased. However, the large value for the tool wear was acquired when the cutting speed increased. In addition, high feed rate and moderate cutting speed caused the formation of the BUE on the cutting inserts. V. P. Astakhov [13] studied the influence of the depth of cut and feed rate on tool wear. Low carbon austenite stainless steel of $18.5 \%$ chromium and $15.5 \%$ nickel has been machined in this study. Results convey that the depth of cut did not affect the rate of the tool wear during the cutting process. S.-T. Kim and Y.-S. Park [14] performed a dry turning experiment to machine the high performance austenite stainless steel. This type of steel has a chromium content of $21 \%$. Flank and notch wear were observed on the cutting insert at a cutting speed of $100 \mathrm{~m} / \mathrm{min}$. Furthermore, high wear and short tool life was observed on the cutting insert at high cutting speed. Ciftici evaluated the cutting tool wear during dry machining of AISA 316 and AISI 304 austenite stainless steel using carbide tools [15]. Xavior MA, Adithan M studied the effects of the coolant on the tool wear during turning of austenite stainless steel. The outcomes revealed that using low feed rate during machining reduced the tool wear and improved the quality of the machined surfaces [16]. The correlations between the tool wear with the cutting speed and feed rate were also studied by Z. Tekıner and S. Yeş1lyurt [17]. In most of the reviewed research studies, Scanning Electron Microscope (SEM) was used to inspect the tool wear and BUE formation on the cutting tool faces. However, Królczyk G, Legutko S, Raos P used Alicona Infinite Focus (AIF) 3D optical profilometer technique to establish the topography of the cutting tool surface [18]. 
The outcomes showed the wear on the tool edge increased when the cutting speed increased.

Maximum and minimum deviation calculations were used to determine the propagation of the wear and buildup edge on the cutting faces. Crater wear and BUE on the rake face can be precisely calculated when (AIF) profilometer is used. From the reviewed literature, it can be seen that machinability studies have been conducted on common austenite stainless steel grades. According to the literature, a research gap exists in literature regards to gradual progress of machining ASS to SASS. As AL6XN has been a classified material so far with limited research conducted on it, this paper aims to continue machining investigation on AL6XN in order to study and analyse the generated wear and surface topography of the cutting edge and BUE formation using Alicona Infinite Focus 3D optical profilometer.

\section{Experimental design}

The chemical composition of the AL6XN alloy has been evaluated using spectrometry. The elements present in the alloy are listed in Table 1. A total of 8 milling trials were executed under a combination of cutting parameters which included cutting speed of 100 and $150 \mathrm{~m} / \mathrm{min}$; feed rates of 0.1 and $0.15 \mathrm{~mm} /$ tooth; and depth of cuts of 2 and $3 \mathrm{~mm}$. Coolant made of phenol-water mixture (1:10) was applied during machining.

Table 2 lists the eight cutting trials that represent the predefined cutting parameters. The selection and the arrangement of the cutting trials were designated according to the recently published study by the authors on machinability of the AL6XN SASS alloy.

Table 1. Chemical composition of AL6XN SASS

\begin{tabular}{|l|l|l|l|l|l|l|l|}
\hline $\mathrm{C}$ & $\mathrm{Si}$ & $\mathrm{Mn}$ & $\mathrm{P}$ & $\mathrm{S}$ & $\mathrm{Cr}$ & $\mathrm{Mo}$ & $\mathrm{Ni}$ \\
\hline 0.026 & 0.36 & 0.37 & 0.044 & 0.002 & 21 & 6.066 & 24 \\
\hline
\end{tabular}

Table 2. List of cutting trials.

\begin{tabular}{|c|c|c|c|}
\hline Trial & $\begin{array}{c}\text { Cutting } \\
\text { speed } \\
(\mathrm{m} / \mathrm{min})\end{array}$ & $\begin{array}{c}\text { Feed/tooth } \\
(\mathrm{mm} / \text { tooth })\end{array}$ & $\begin{array}{c}\text { Cutting } \\
\text { depth }(\mathrm{mm})\end{array}$ \\
\hline 1 & 100 & 0.1 & 2 \\
\hline 2 & 100 & 0.1 & 3 \\
\hline 3 & 100 & 0.15 & 2 \\
\hline 4 & 100 & 0.15 & 3 \\
\hline 5 & 150 & 0.1 & 2 \\
\hline 6 & 150 & 0.1 & 3 \\
\hline 7 & 150 & 0.15 & 2 \\
\hline 8 & 150 & 0.15 & 3 \\
\hline
\end{tabular}

Machining trials were conducted on 5-Axis CNC milling machine (SPINNER U620) having specification of spindle power, $15 \mathrm{~kW}$ and a table diameter of $650 \mathrm{~mm}$. Insert type cutting tool-ISCAR HELIDO 490-09 grade IC830, TiCN, TiN coated inserts were used for the trials. The designation of the cutting insert according to the manufacturer standards is H490 ANCX 090416PDR. The cutting insert has 4 cutting edges and a $0.8 \mathrm{~mm}$ nose radius. This type of insert is used in rough and hard machining applications.
The cutting tool holder was designed to clamp two cutting inserts. Each cutting insert has four cutting edges of $0.8 \mathrm{~mm}$ radius per edge. A new cutting edge was used for each cutting trial in order to maintain reference (zero) tool wear condition. The workpiece of a rectangular block configuration was fixed on the milling dynamometer as shown in Fig. 1. The cutting time was constant and equal to 20 seconds per trial during the cutting process. Side by side cutting process was executed and eight machined bays were formed on the mounted alloy.

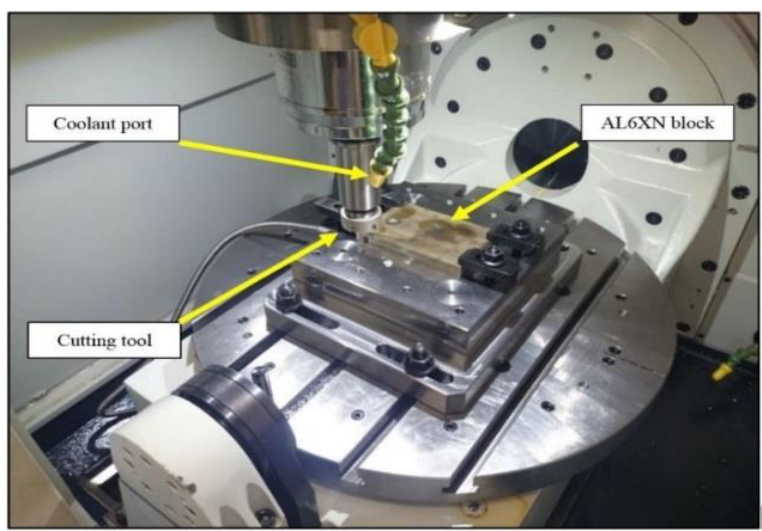

Figure 1. Experimental setup.

\subsection{Tool wear measurements using Alicona Infinite Focus 3D optical profilometer}

The worn cutting inserts were scanned using Alicona Infinite Focus (AIF) 3D optical surface profilometer. The cutting insert was fixed on to a customised tool holder which can scan sample at inclination angles from $0^{\circ}$ to $35^{\circ}$ as shown in Fig. 2 . The best scan quality was obtained at $25^{\circ}$. A full scan was performed on a new cutting edge which was later used as a reference edge. Later, the worn edge was scanned using same elected scanning coordinates of the new cutting edge. Using difference analysis available on IF-Measure Suite 5.1 software, the new and worn cutting edges were superimposed to evaluate the tool wear (blue region as shown in Fig. 2).
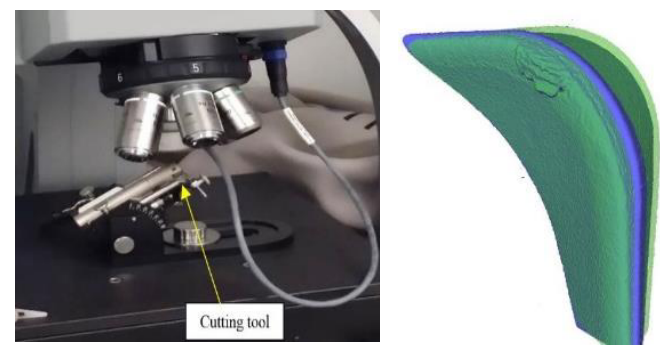

Figure 2. Fixing the tool holder with the cutting inserts on the stage of the AIF device and difference analysis of cutting tool wear using Alicona optical surface profilometry.

\section{Results and discussion}

Four wear types were identified on the edges of the cutting tool when the AIF scanning was run on the cutting inserts as shown in Fig. 3. 


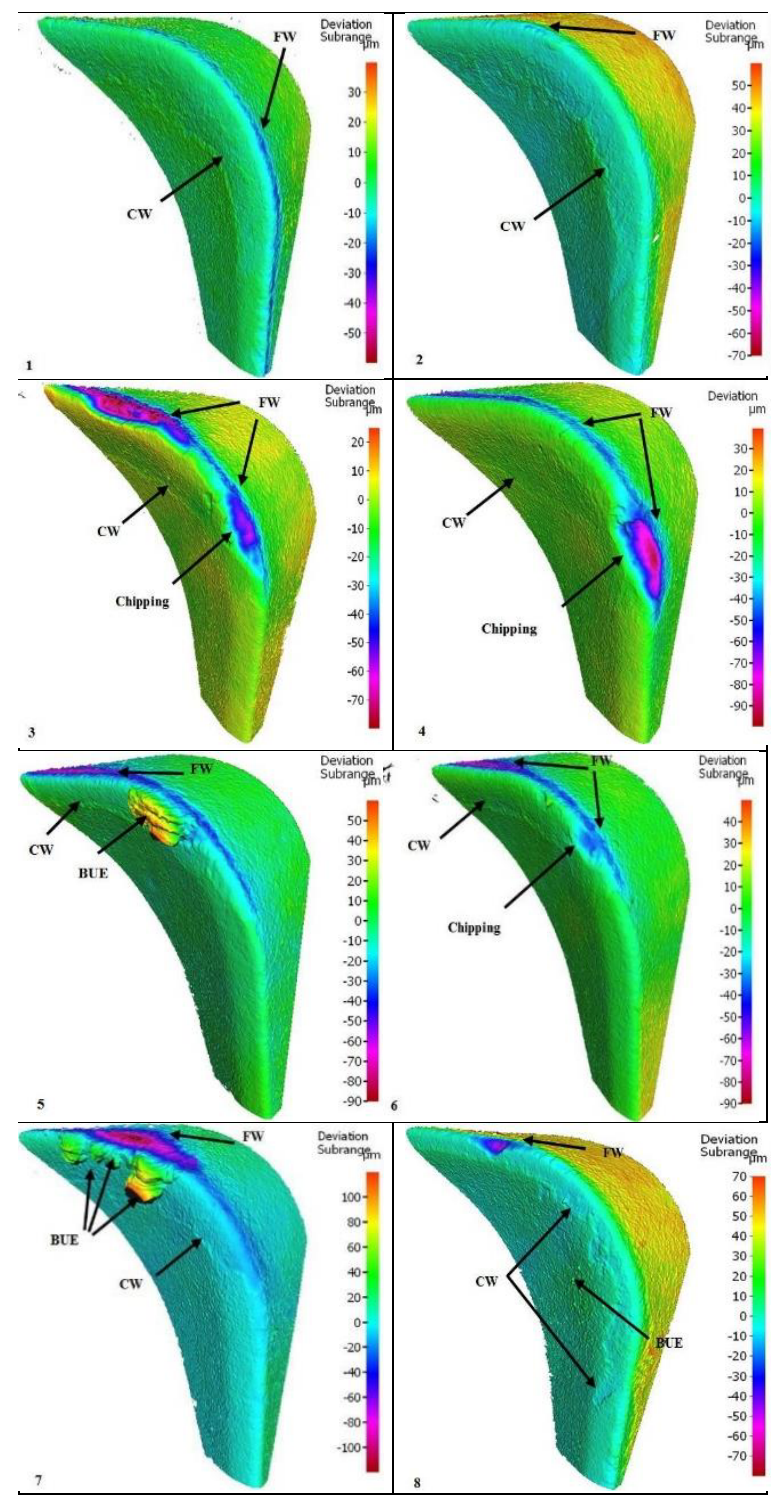

Figure 3. Inspection of the Crater Wear (CW), Flank Wear (FW), Chipping and BUE on the cutting edges of the 8 cutting inserts.

\subsection{Flank wear}

Flank Wear (FW) was observed in all the cutting trials but with different values as shown in Fig. 3. Flank wear was found to increase when the feed rate was increased from $0.1 \mathrm{~mm} /$ tooth in trial 2 to $0.15 \mathrm{~mm} /$ tooth in trial 3 and trial 7. The effect of the depth of cut on the flank wear was also observed in trials 2 and 3 . Reducing the depth of cut from $3 \mathrm{~mm}$ to $2 \mathrm{~mm}$ led to increase in flank wear as in trial 3 . In trial 7 , changing the depth of cut from $3 \mathrm{~mm}$ to $2 \mathrm{~mm}$ also caused the flank wear on the insert edge. Generally, when the cutting speed was elevated from $100 \mathrm{~m} / \mathrm{min}$ to $150 \mathrm{~m} / \mathrm{min}$ the flank wear was reduced.

\subsection{Crater wear}

The rake faces of the inserts suffered from the presence of the crater wear. In Fig. 3, the Crater Wear (CW) was observed in all the trials but with different values. Figure
7 shows that applying a cutting speed of $100 \mathrm{~m} / \mathrm{min}$ while increasing the feed from 0.1 to $0.15 \mathrm{~mm} /$ tooth increased the $\mathrm{CW}$ in trials 3 and 4 . Such an increase was found to be larger than the $\mathrm{CW}$ in trials 1 and 2 . Changing the speed to $150 \mathrm{~m} / \mathrm{min}$ caused a significant wear on the rake faces of the inserts in the last four trials. In other words, high speed, as well as high feed rate, used in trials 7 and 8 produced a large crater wear.

\subsection{Chipping wear}

Chipping wear is the separation of small parts from the cutting tool edge. This type of wear occurred when the material was machined under trials 3 and 4 cutting conditions, as shown in Fig. 3, due to the use of a high feed with a low cutting speed.

\subsection{Build-Up Edge (BUE)}

The formation of BUE was detected when the cutting edges were scanned. Fig. 3 shows the presence of the BUE in trials 5, 7 and 8 . At a $150 \mathrm{~m} / \mathrm{min}$ cutting speed, the BUE was formed on the rake face of the cutting insert used in trial 5. Keeping the cutting speed and the depth of cut constants and increasing the feed rate to 0.15 $\mathrm{mm} /$ tooth in the trial 7 led to increase the BUE formation. In trial 8 , a feed rate of $0.15 \mathrm{~mm} /$ tooth and a depth of cut of $3 \mathrm{~mm}$ lowered and limited the formation of the BUE on the rake face as shown in Fig. 3.

\subsection{Tool wears statistical results obtained by the optical profilometer}

The statistics obtained from AIF can be presented by the minimum and maximum deviation. Minimum deviation reveals the magnitude of the formed BUE whereas the maximum deviation is an indicator of how much the cutting edge is lowered [18]. The inserts of the cutting trials 5 and 7 have the BUE formed and their minimum deviations magnitudes were equal to $368 \mu \mathrm{m}$ and $152 \mu \mathrm{m}$ respectively.

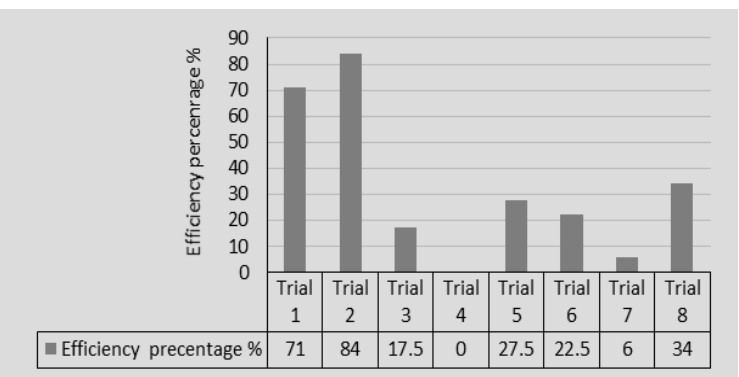

Figure 4. Efficiency percentages of the 8 cutting edges.

The BUE was measured and Table 3 lists the minimum and maximum deviations of the eight cutting edges. It can be seen from table 3 that the cutting parameters used in trials 1, 3, 6 and 7 lowered the cutting edges more in comparison to the other cutting trials. Such lowered cutting edge causes tool failure and as a consequence, shortens the tool life. Maximum value of the maximum deviation was placed in the cutting trial 
number 4 and nominated as the lowest effective edge during machining. This value was used as a reference to estimate the efficiency percentages of the cutting edges. Fig. 4 shows the efficiency percentage of each cutting trial calculated regarding to trial 4.

Table 3. BUE and the lowered cutting edge measurements using AIF statistics.

\begin{tabular}{|c|c|c|c|c|c|c|c|c|}
\hline Trial & 1 & 2 & 3 & 4 & 5 & 6 & 7 & 8 \\
\hline $\begin{array}{c}\text { Maximum } \\
\text { deviation } \\
(\mu \mathrm{m})\end{array}$ & 35 & 20 & 99 & 120 & 87 & 93 & 113 & 79 \\
\hline
\end{tabular}

The maximum efficiency percentage of the cutting edge was achieved in trial 2 where the low speed, feed rate were applied. The efficiency was reduced to $17.5 \%$ in trial 3, and the minimum efficiency was recorded in trial 4 due to the occurrence of the chipping wear. When the cutting speed increased to $150 \mathrm{~m} / \mathrm{min}$, the efficiencies of the cutting edges were reduced in trials 5 and 6 and the minimum efficiency value at high cutting speed was equal to $6 \%$ in trial 7 due to the existence of the BUE.

\section{Conclusion}

Super Austenitic Stainless Steel alloy-AL6XN is hard to be machined material. Machinability test was conducted under a combination of various cutting parameters. The cutting inserts used were inspected for tool wear using Alicona Infinite Focus 3D optical profilometer.

1. Flank wear was obtained with low amounts on the flank faces of the cutting inserts.

2. Crater wear was located on the rake faces of all the cutting inserts with a varied length and depth. Maximum crater wear length of $2624 \mu \mathrm{m}$ and maximum depth of $380 \mu \mathrm{m}$ was obtained in trial 1 and 4 respectively. The length and the depth of the crater wear decreased up to $58 \%$ and $71 \%$ respectively in trial 2 where the low speed and feed with high depth of cut were applied.

3. Significant BUE was located on the rake faces of the cutting inserts in trials 5 and 7 in which high cutting speed, depth of cut and low feed rate were applied.

4. Chipping wear, was found in the cutting trials 3,4 and 6 .

5. Minimum and maximum deviations received from the alignment process of the new and worn cutting edges present the magnitude of the BUE and the lowered cutting edges respectively. Maximum deviation values were used to calculate the efficiency percentages of the cutting tools. Maximum efficiency of $84 \%$ was gained at low cutting speed and feed rate in trial 2 whereas minimum efficiency was gathered at cutting trial 4 due to the presence of the chipping wear. At high speed and feed rate in trial 7 , the formed BUE lowered the efficiency of the cutting edge to $6 \%$.

\section{References}

1. F.H. Abed, G.Z. Voyiadjis, Int. J. Plast. 21(8): p. 1618-1639, (2005).

2. S. Kalnaus, F. Fan, A.K. Vasudevan, Y. Jiang, Eng. Fract. Mech. 75(8): p. 2002-2019, (2008).

3. S. Nemat-Nasser, W.-G. Guo, D.P. Kihl, J. Mech. Phys. Solids. 49(8): p. 1823-1846, (2001).

4. S. Kalpakjian, S.R. Schmid, Manufacturing engineering and technology, (2014).

5. M.P. Groover, Fundamentals of modern manufacturing: materials processes, and systems, (2007).

6. M.M.C.A.P. Handbook, Inc., Sweden, (1997).

7. T. Akasawa, H. Sakurai, M. Nakamura, T. Tanaka, K. Takano, J. Mater. Process. Technol. 143: p. 66-71, (2003).

8. T. Kosa, R. Ney, ASM Handbook. 16: p. 681-707, (1989).

9. J. Kopač, S. Šali, Journal of Materials Processing Technology. 113(1-3): p. 312-316, (2001).

10. A. Polishetty, M.F.A. Alabdullah, N. Pillay, G. Littlefair. ASME Proceedings Advanced Manufacturing (2015).

11. M. Nordin, R. Sundström, T.I. Selinder, S. Hogmark, Surf. Coat. Technol. 133-134: p. 240-246, (2000).

12. K. Abou-El-Hossein, Z. Yahya, J. Mater. Process. Technol. 162: p. 596-602, (2005).

13. V.P. Astakhov, Int. J. Adv. Manuf. Technol. 34(7-8): p. 631-640, (2007).

14. S.-T. Kim, Y.-S. Park, Met. Mater. Int. 15(2): p. 221230, (2009)

15. I. Ciftci, Tribol. Int. 39(6): p. 565-569, (2006).

16. M.A. Xavior, M. Adithan, J. Mater. Process. Technol. 209(2): p. 900-909, (2009).

17. Z. Tekıner, S. Yeşılyurt, Mater. Des. 25(6): p. $507-$ 513, (2004).

18. G. Królczyk, S. Legutko, P. Raos, Tehn. vjesn. Tech. Gaze. 20(3): p. 413-418, (2013). 